\title{
EVALUATION OF EQUIVALENT STIFFNESS AND MAXIMUM AXIAL LOAD OF M2-PANEL SYSTEM WALLS
}

\author{
A. M. Hilal \\ Structural Department, Faculty of Engineering Al-Azhar University

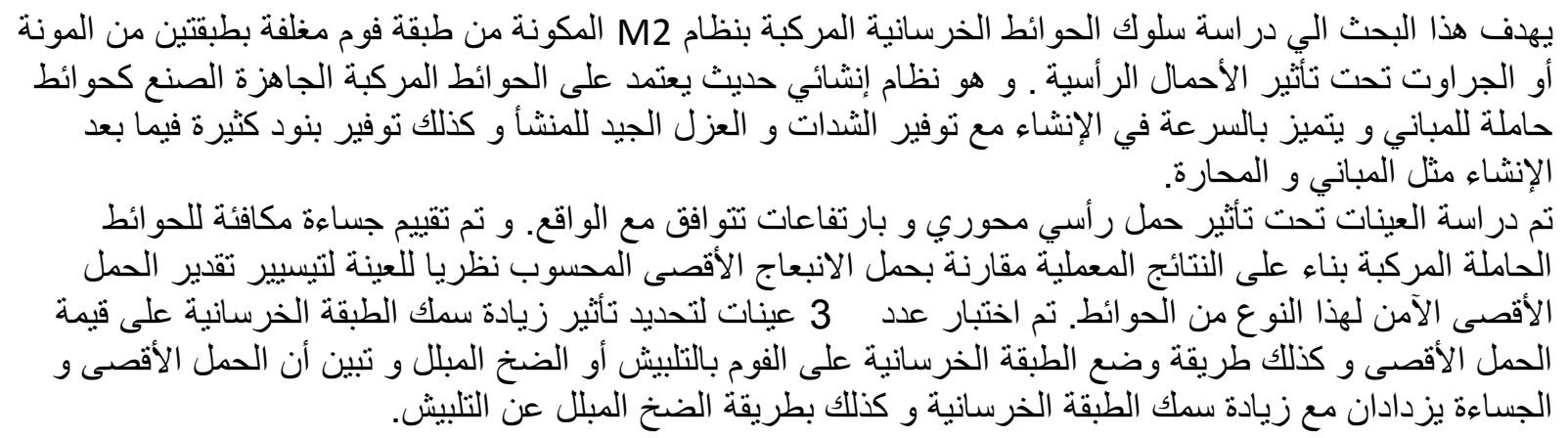

\begin{abstract}
A new construction method depending on composite panels composed of a Polystyrene corrugated layer surrounded by two concrete layers is tested to prove its effectiveness as wall bearing panels. 3 different full scale specimen $1000 \mathrm{~mm}$ wide and $3000 \mathrm{~mm}$ high were fabricated and tested under centric axial load. The tested variables were the thickness of concrete layers surrounding the foam layer and the method of concrete application. Thicknesses of 30 and $35 \mathrm{~mm}$ were used and wet shot-crete vs. manual concrete application were evaluated.

Test results were analyzed to assess the maximum safe axial load that could be carried by this type of wall, also the equivalent effective stiffness for the walls according to load-lateral deformation behavior was dedicated.

Results showed the higher the concrete thickness was, the more load it carried, also showed an increase of axial load capacity for the wet shot-crete method of concrete application over the manual concrete application.
\end{abstract}

\section{KEYWORDS: M2 Panels, Polystyrene, Composite Action, Wall Bearing, Axial Load, Equivalent Wall Stiffness.}

\section{INTRODUCTION}

Structural Insulated Panel Building Systems are one of the newest building systems available in today's building materials market. Despite of its limitation of having wide span openings it is considered to be one of the easiest ways to construct economic house units [1], [2]. The M2-panel Building System consists of two types: floor panel and wall panel. The use of M2 panels allows the construction of less energy-greedy buildings, ensuring higher energy efficiency and thereby energy savings up to $80 \%$ throughout its life cycle [3].

The M2 panel system is a building system that combines in a single element all the functions needed to create a complete architectural system ensuring maximum efficiency with all types 
of construction as: speed installation, lightness, thermal insulation, earthquake resistance, fire resistance, and blast resistance [4],[5].

The M2 Building System composed of polystyrene board imbedded in concrete composite with prefabricated zinc coated steel wire mesh reinforcement; this system consists of two types, single panel, and double panel. Both wall panel types have $3 \mathrm{~mm}$ diameter zinc coated steel wire mesh reinforcement at $65 \mathrm{~mm}$ centres on each face [6]. The M2 single panel is designed for use in the construction of two to six-storey residential buildings [7], [8].

This paper compares between three wall bearing systems, showing the maximum safe axial capacity for each system. The load - lateral deformation behavior for each wall was also described showing their fulfillment to mechanical requirements in the Egyptian Specifications [9], [10].

\section{Literature Review}

Numerous laboratory tests carried out in several countries have shown the high load resistance of the M2 panels. For example, compression tests with a centered load carried out on a finished single panel, $270 \mathrm{~cm}$ high, have shown a maximum load up to $156 \mathrm{ton} / \mathrm{m}$ [11].

The M2 Building System provides a robust system that has a high resistance to hard and soft body impacts likely to be associated with normal use situations. The rendered wall is acceptable for all normal situations. This includes Category B in Table 2 of BS 8200:1985. Category A involves external walls of houses and public buildings in vandal prone areas prone to vandalism and abnormally rough use and some image could be expected to occur to the rendering in this type of location.

The basic element of the M2 building system is a modular non prefabricated panel, made up of two electro-welded steel wire meshes, linked each other by connectors, sandwiching a polystyrene foam slab suitably shaped. Figure 1 shows a schematic prefabricated wall panel, while Figure 2 shows a wall under construction.

\section{Galvanized Steel Wire}
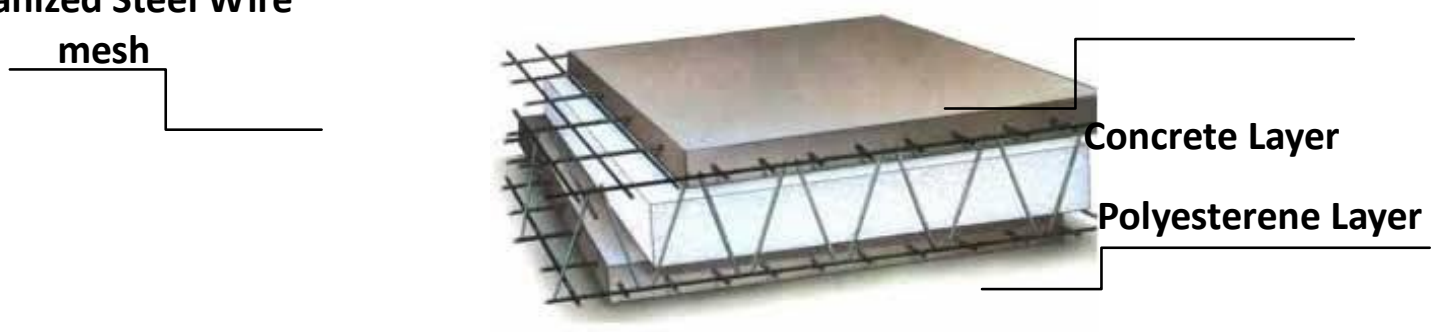

Fig. 1. Schematic M2-panel wall

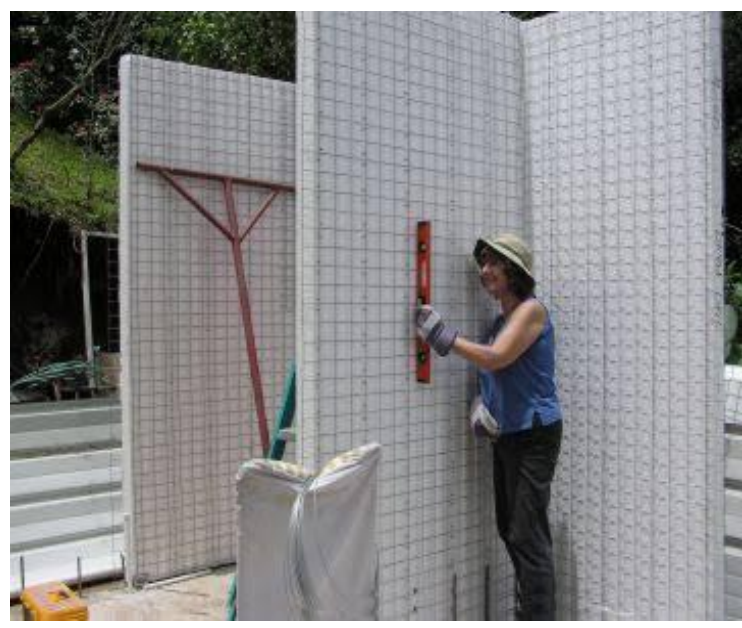

Fig. 2. M2-panel wall under construction

Produced on an industrial scale the panel is then assembled and cast-in-place using shotcrete. The monolithic joints of the M2 building system are suitable to give constructions high structural strength. Laboratory tests carried out on full-scale prototype houses have shown 
that the M2 structures withstand, without damage, earthquakes with intensities much greater than those considered by current regulations. In fact, during laboratory tests on full-scale prototypes, natural and artificial accelerometers were simulated up to peaks of more than 1.0 $\mathrm{g}$, and no damage was detected [12].

The results obtained during these tests scientifically confirm what has already happened and often experienced in nature. In fact the structures built with M2 panels are extremely light, so with a reduced seismic mass, but are also rigid, thanks to two sheets of reinforced plaster that interact with each other creating a box-like behaviour of the entire structure.

\section{Experimental program}

The experimental program consisted of three full scale walls with constant width of $1000 \mathrm{~mm}$ and constant height of $3000 \mathrm{~mm}$. The $40 \mathrm{~mm}$ thick corrugated Polystyrene layer and the wire mesh were also constant in the three specimen. Wall W1 had concrete thickness of $35 \mathrm{~mm}$ on each side of the polystyrene layer with wet shot-crete as method of concrete application, while wall W2 had a concrete thickness of only $30 \mathrm{~mm}$ with the same method of application and wall W3 had $35 \mathrm{~mm}$ concrete layer thickness with manual application of concrete. The specimen variables and geometric properties are shown in Table1. Figure 3 shows the plan of specimen.

\begin{tabular}{|c|c|c|c|c|c|}
\hline & Table 1. Properties and Variables of Specimen \\
\begin{tabular}{|c|c|c|c|c|c|}
\hline Specimen No. & B (mm) & H $(\mathbf{m m})$ & $\begin{array}{c}\text { Concrete } \\
\text { thickness }\end{array}$ & $\begin{array}{c}\text { concrete } \\
\text { app. }\end{array}$ & $\begin{array}{c}\text { fcu } \\
(\mathbf{M P a})\end{array}$ \\
\hline W1 & 1000 & 3000 & $35 \mathrm{~mm}$ & shot-crete & 32 \\
\hline W2 & 1000 & 3000 & $30 \mathrm{~mm}$ & shot-crete & 32 \\
\hline W3 & 1000 & 3000 & $35 \mathrm{~mm}$ & manual & 32 \\
\hline
\end{tabular}
\end{tabular}

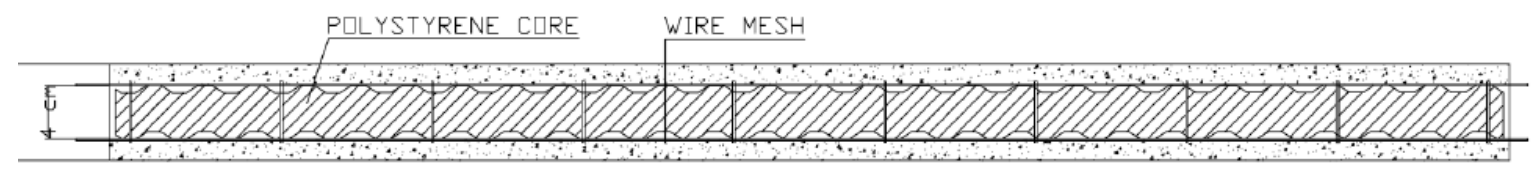

Fig. 3. Sketch of Specimen

Shot-crete was applied by three equally thick layers. 6 concrete cubes were taken from the concrete mix used. 3 were tested after 7 days, while the other 3 were tested after 28 days at the day of test, giving an average concrete compressive strength of 32MPa after 28 days. The Polystyrene compressive strength was neglected in comparison of concrete compressive strength and it was only used as a fill material. A rigid concrete beam from the same concrete mix with a width of $80 \mathrm{~mm}$ and a height of $250 \mathrm{~mm}$ was cast on top of the specimen to ensure with a steel beam with the same height a uniform distribution of the axial load along the whole width of the walls. At the bottom of the walls a 300x300 mm reinforced concrete beam acted as bottom support of the walls. Figure 4 shows the three walls before concrete application, while Figure 5 shows the application of shot-crete on wall W2.

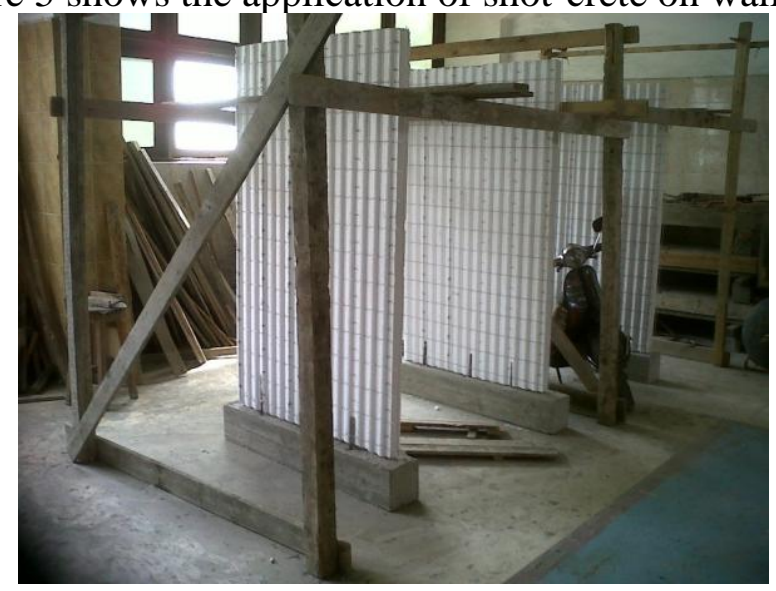

Fig. 4. The three walls before concrete casting 


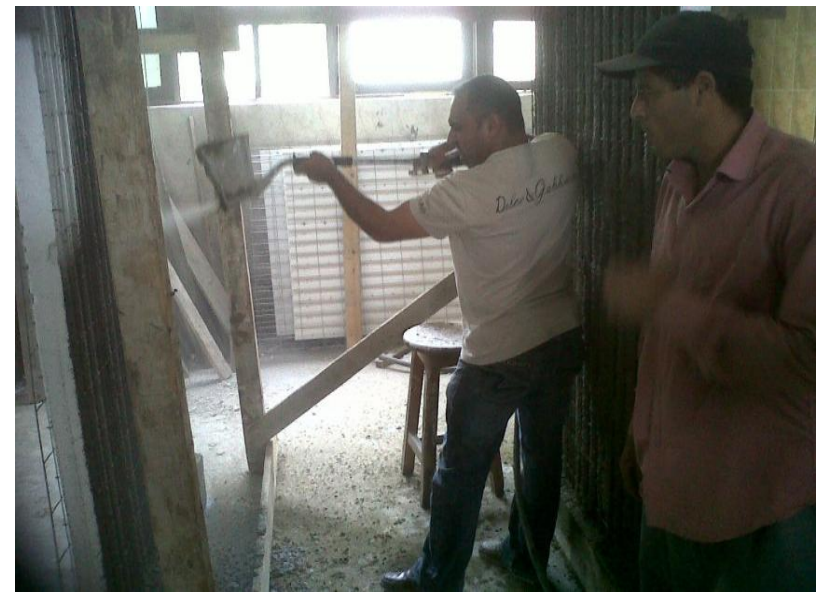

Fig. 5. Application of shot-crete on wall W2

4 LVDTs were arranged uniformly at the mid-height of the walls during testing to measure the lateral deformation, and two vertical LVDTs were put to measure the vertical deflection of the specimen. A 200 ton hydraulic jack was used to act vertically on the walls as shown in Figure 6.

At the age of 28 days the specimen were tested up to failure using displacement control method. The data was collected on a Data-Acquisition-System and then exported to excel to draw different load- deformation relations.

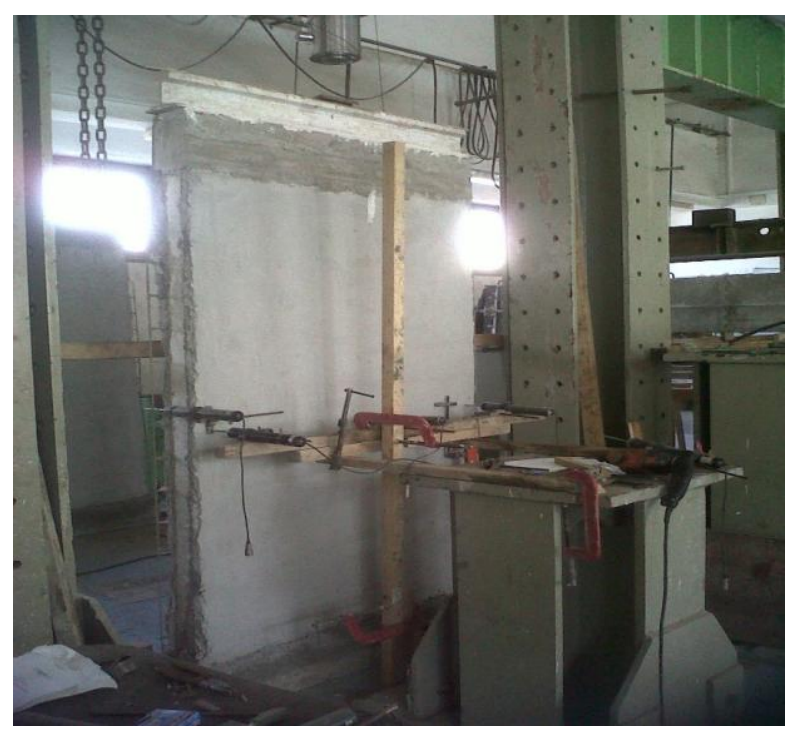

Fig. 6. Test Setup

\section{RESULTS}

Form the observed behavior of the tested walls the following remarks were concluded:

\subsection{Wall W1}

Wall W1 with concrete layer thickness of $35 \mathrm{~mm}$ and shot-crete as method of concrete application showed a first horizontal hair crack at mid-height of the specimen at a load of about $160 \mathrm{kN}$. The specimen carried load up to $600 \mathrm{kN}$ when a large lateral deformation started to appear. It failed at a maximum axial load of $750 \mathrm{kN}$ due to outside plane buckling. The maximum lateral deformation observed was about $7 \mathrm{~mm}$ at failure, while the axial deformation of the wall was of minor effect. Figure 7 shows the specimen after failure, while Figure 8 shows the load-lateral deformation relation of the wall throughout its loading phase.

\subsection{Wall W2}

Wall W2 with concrete layer thickness of $30 \mathrm{~mm}$ and shot-crete as method of concrete application showed a first horizontal hair crack at mid-height of the specimen at a load of about $70 \mathrm{kN}$. The specimen carried load up to $500 \mathrm{kN}$ when it started to suffer several vertical and horizontal cracks and a large lateral deformation started to appear. It failed at a maximum 
axial load of $570 \mathrm{kN}$ due to outside plane buckling. The maximum lateral deformation observed was about $12 \mathrm{~mm}$ at failure, while the axial deformation of the wall was of minor effect. Figure 9 shows the load-lateral deformation relation of the wall throughout its loading phase.

\subsection{Wall W3}

Wall W3 with concrete layer thickness of $35 \mathrm{~mm}$ and manual application as method of concrete application showed a first horizontal crack at mid-height of the specimen at a load of about $50 \mathrm{kN}$. The specimen carried load up to $460 \mathrm{kN}$ when it started to have several vertical and horizontal cracks and a large lateral deformation started to appear. It failed at a maximum axial load of $520 \mathrm{kN}$ due to outside plane buckling. The maximum lateral deformation observed was about $18 \mathrm{~mm}$ at failure, while the axial deformation of the wall was about $2 \mathrm{~mm}$ at failure. Figure 10 shows the specimen after failure, while Figure 11 shows the load-lateral deformation relation of the wall and Figure 12 shows the axial deformation of all specimen.

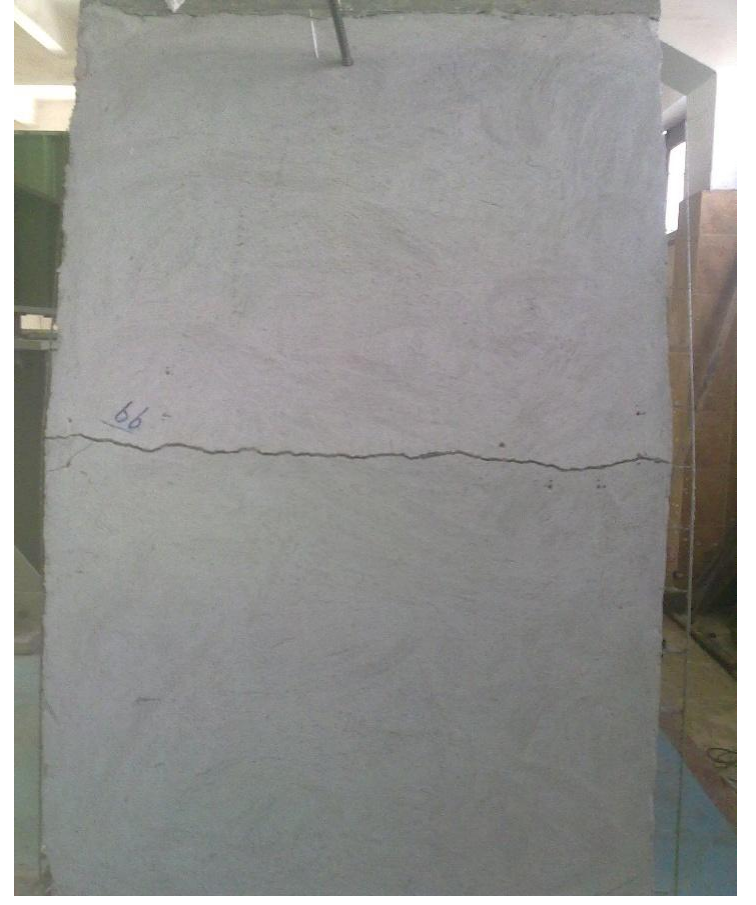

Fig. 7. Failure of Wall W1

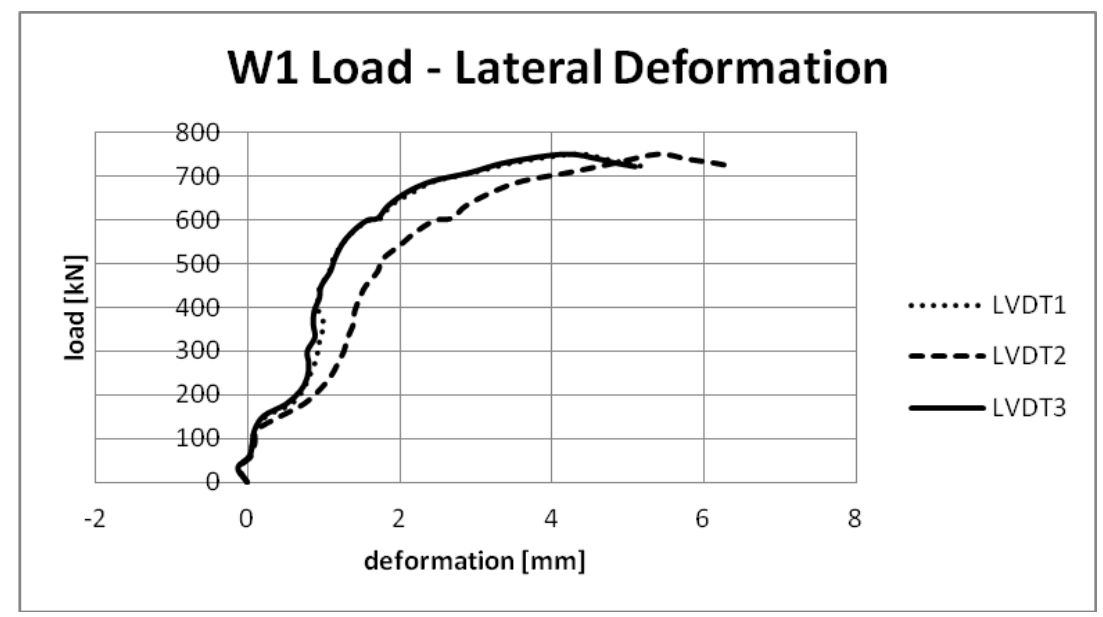

Fig. 8. Load - Lateral Deformation of Wall W1 at mid-height 


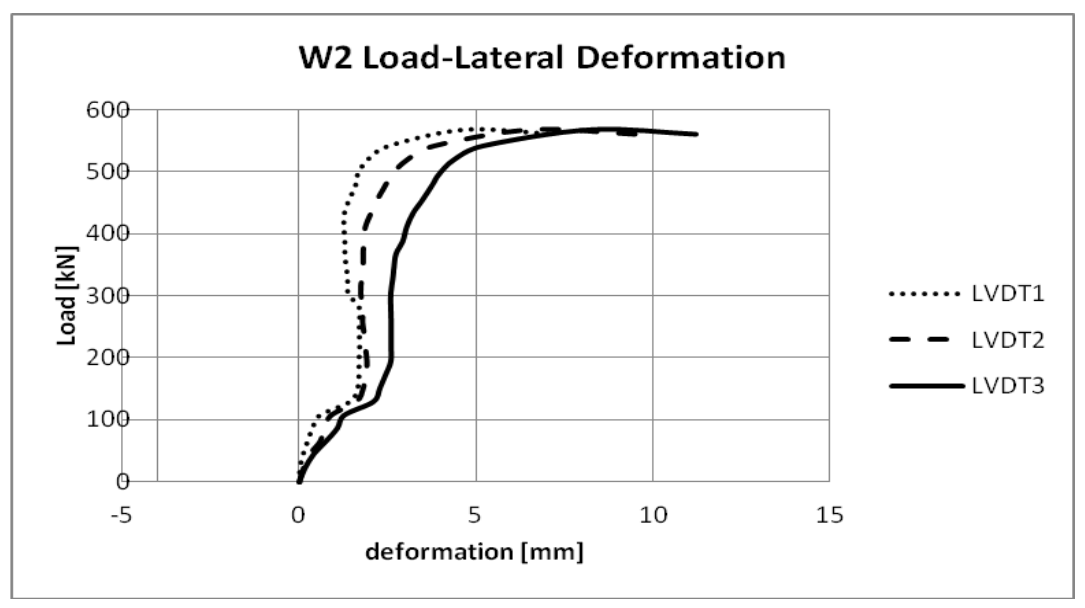

Fig. 9. Load - Lateral Deformation of Wall W2 at mid-height

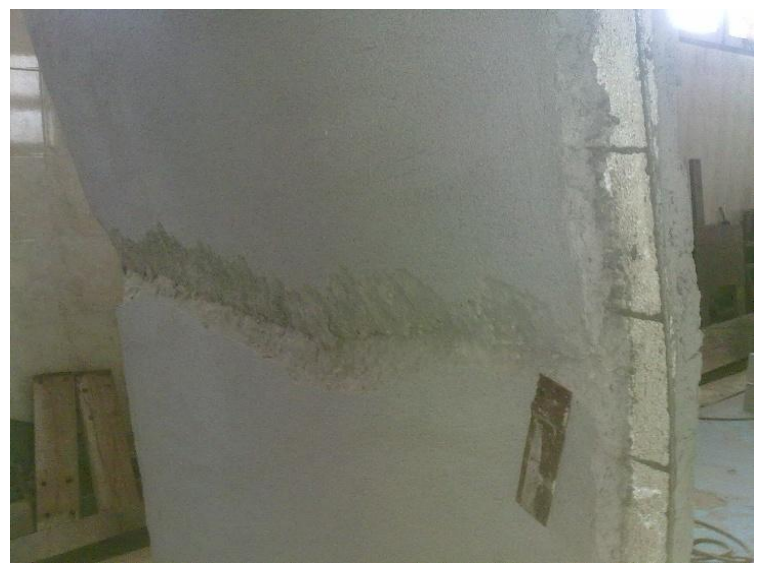

Figure 10. Failure of Wall W3

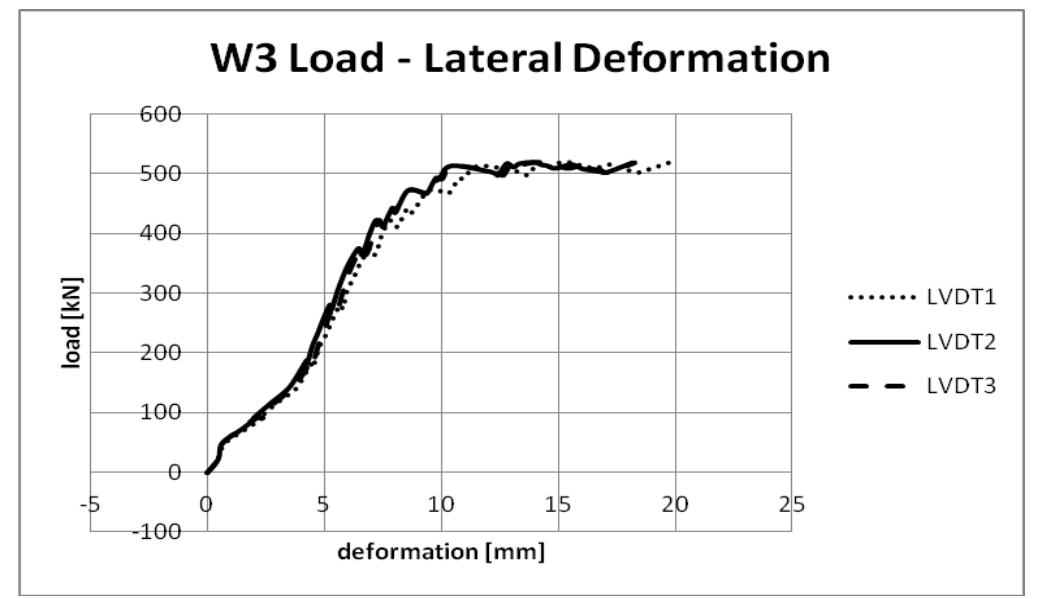

Fig. 11. Load - Lateral Deformation of Wall W3 at mid-height 


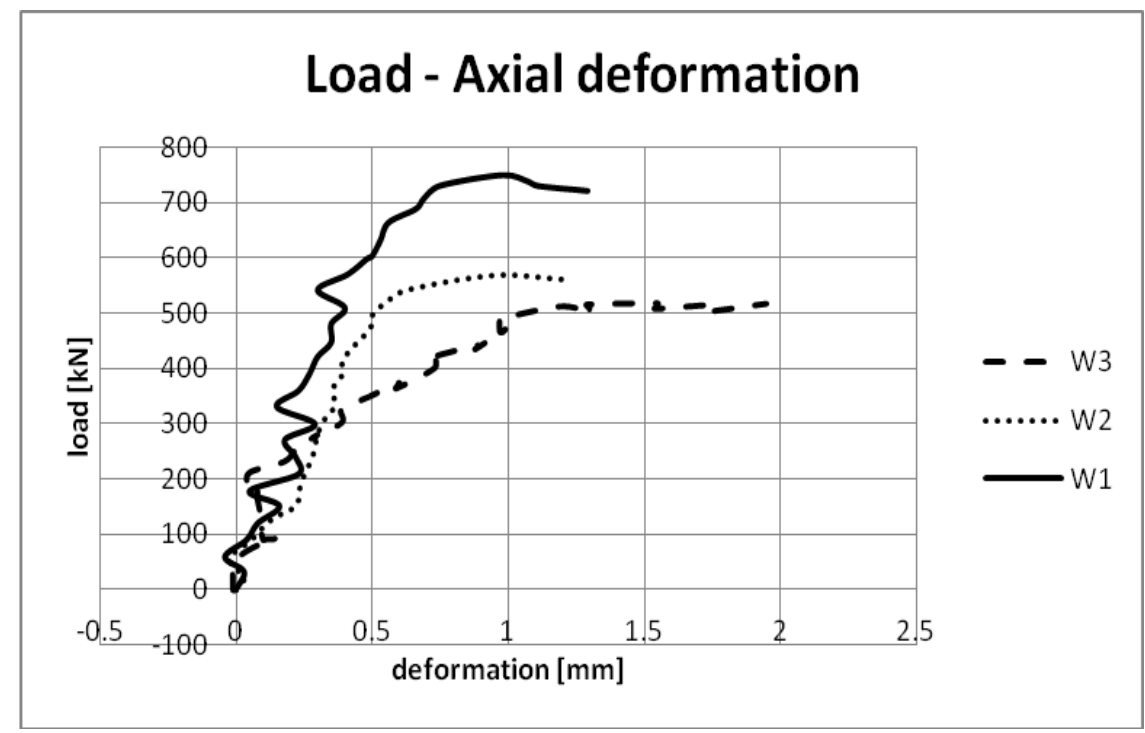

Fig. 12. Load - Axial Deformation of Walls

Table 2. shows a brief summary of the collected test results, while Figure 13 shows the maximum axial load for all specimen.

Table 2. Cracking load and failure load for experimental results

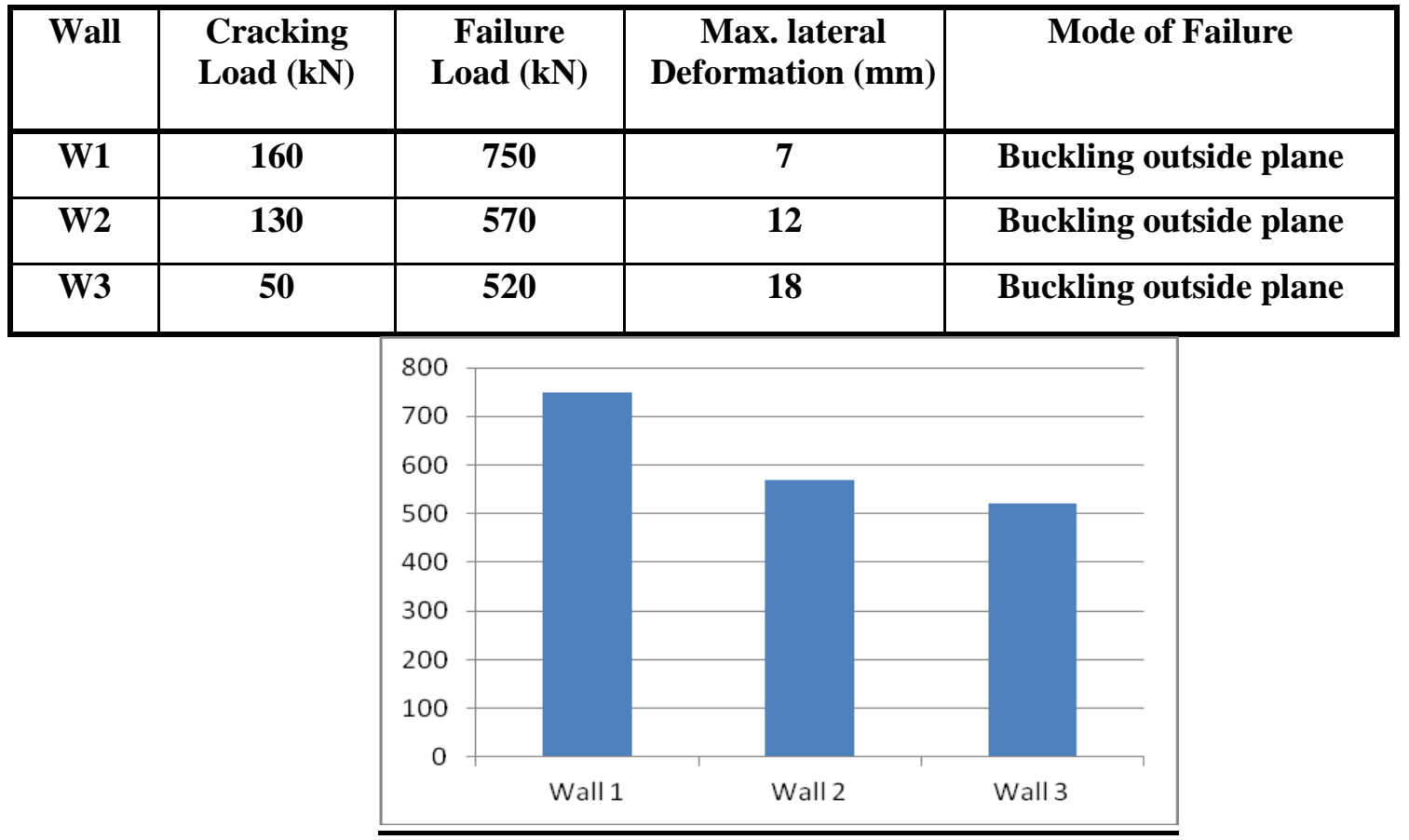

Fig. 13. Maximum Axial Load of Walls

\section{ANALYSIS OF RESULTS}

The tests showed that all specimen carried a high axial load and failed due outside plane buckling due to the high slenderness ratio. The increase of thickness of concrete layers by only $15 \%$ resulted in an increase of cracking load and maximum axial load of about 25-30\% for the same concrete method of application. Wall W3 carried only $70 \%$ of the W1 cracking and maximum axial load due to the poor method of manual concrete application. The stiffness of the walls in resisting buckling had a significant role in this results. It would be an underestimation of the composite section to deal with as two independent layers of concrete. The two concrete layers acted together and the overall stiffness of the section had to be 
estimated. The well-known Euler formula for the buckling load of columns was applied to try to evaluate a reasonable equivalent stiffness for the composite section.

$P_{c}=\frac{\pi^{2} \times E I}{k \times L^{2}}$

Where;

EI is the effective stiffness of the member,

$\mathrm{L}$ is the unsupported length,

And $\mathrm{k}$ is the effective length factor.

The assumption of the ACI 318M-08 [13] as well as the CSA Standard A23.3-04 [1 4] was used to evaluate the effective stiffness of the walls.

Equation (10-15) of the ACI - Code states that

$$
\mathbf{E I}=\frac{0.4 \times E_{c} \times I_{g}}{1+\beta_{\text {dns }}}
$$

where;

$\square_{\text {dns }}$ is the ratio between the maximum factored axial sustained load to the maximum factored axial load and could be taken $=0.6$.

Therefore, equation [2] becomes

$\mathrm{EI}=0.25 \mathrm{E}_{\mathrm{c}} \mathrm{I}_{\mathrm{g}}$

As for the Canadian Code CSA - Standards it states directly in Equation (10-19) that EI = $0.25 \mathrm{E}_{\mathrm{c}} \mathrm{I}_{\mathrm{g}}$.

The gross inertia of the sections was calculated neglecting the effect of Polystyrene and also neglecting the effect of the light wire mesh reinforcement of the members. The walls were assumed fully composite, and $\mathrm{P}_{\mathrm{c}}$ was calculated for each wall. Table 3 shows the results of the maximum calculated axial loads and a comparison between the experimental and calculated loads.

Table 3. Comparison between theoretical and experimental results.

\begin{tabular}{|c|c|c|c|}
\hline Specimen ID & W1 & W2 & W3 \\
\hline $\mathbf{k}$ & 1 & 1 & 1 \\
\hline Wall Height H (mm) & 3000 & 3000 & 3000 \\
\hline$E_{c}\left(N / m^{2}\right)$ & 24890.159 & 24890.159 & 24890.159 \\
\hline $\mathbf{I}_{\mathrm{g}}(\mathbf{m m} \mathbf{4})$ & 105583333 & 78000000 & 105583333 \\
\hline $\mathbf{E}_{\mathrm{c}} \mathbf{I}_{\mathrm{g}}(\mathrm{Nmm} 2)$ & $2.628 \mathrm{E}+12$ & $1.941 \mathrm{E}+12$ & $2.628 \mathrm{E}+12$ \\
\hline $0.25 \mathrm{E}_{\mathrm{c}} \mathbf{I}_{\mathrm{g}}$ & $6.57 \mathrm{E}+11$ & $4.854 \mathrm{E}+11$ & $6.57 \mathrm{E}+11$ \\
\hline $\mathbf{P}_{\mathbf{c}}(\mathbf{k N})$ & 719.74694 & 531.71519 & 719.74694 \\
\hline $\mathbf{P}_{\text {exp. }}(\mathbf{k N})$ & 750 & 570 & 520 \\
\hline $\mathbf{P}_{\text {exp. }} / \mathbf{P}_{\mathbf{c}}$ & 1.0420329 & 1.0720025 & 0.7224761 \\
\hline
\end{tabular}

The comparison shows good agreement between the experimental and analytical results with 4-7\% difference in loads in walls $\mathrm{W} 1$ and $\mathrm{W} 2$, where shot-crete was used. The theoretical load was based on the ACI equation to evaluate the effective stiffness for slender columns.

Wall W3 though, shows poorer response to the equation and the actual capacity was only $72 \%$ of the theoretical one.

\section{CONCLUSIONS}

In views of the obtained results and comparisons, the main conclusions which can be drawn are as follows:

1) Composite walls of $M 2$ system do act safely as wall bearing members carrying axial loads and resisting buckling. 
2) The axial load capacity of the walls was not governing in the experimental program, but outside plane buckling was the governing failure mechanism. This was due to the geometric properties (high slenderness) of the specimen.

3) The increase of thickness of concrete layer results in increasing the capacity of the cross section by the ratio of the effective stiffness and not by the area ratio.

4) The increase of thickness of concrete layers by only $15 \%$ resulted in an increase of cracking load and maximum axial load of about $25-30 \%$ for the same concrete method of application.

5) The capacity of the wall deteriorates when manual concrete application is used instead of shot-crete by about $40 \%$. So for the use of manual application of concrete the maximum safe design load has to be racdically reduced.

6) The assumption of the effective stiffness $E I=0.25 \mathrm{E}_{\mathrm{c}} \mathrm{I}_{\mathrm{g}}$ taken from the American and Canadian Codes matches with very good agreement to evaluate the effective stiffness of the M2 walls, provided shot-crete is used to apply concrete layers.

\section{REFERENCES}

[1] A.El-alfy, A.Shalaby, A Comparative Study between Wall Bearing Steel Reinforced Expanded Polystyrene Composite Wall System and Insulated Concrete Forms, (2011).

[2] Yehia A. M., Sherif. E. Z., Osama. A. S., Tayseer K. M., and Eslam M., Test Results Report on Innovida Sandwich Panels, Test report made on Concrete Construction Test Laboratory CCTL on Housing and Building National Research Center HBRC, Egypt October 2008.

[3] Alberto A., Antonio B., Emanuela S., Static Tests of the Emmedue Construction System, Tests made on Research and Technology Laboratory of Perugia University, September 2000.

[4] J. M. Davis, Lightweight Sandwich Construction, University of Manchester, U. K., 2001.

[5] Oscar M. Ramirez, Jose G., Jose S., Eduardo G., Experimental Tests on M2 Panel System, Tests made on Panama Technology University, September 2003.

[6] M.G. Megahed, Behavior of sandwich wire mesh concrete slabs, thesis for Master degree, Cairo University, 2009

[7] A. Benayoune, A.A.A Samad., A.A. Abang Ali, D.N. Trikha, Response of Precast Reinforced Composite Sandwich Panels To Axial Loading, Journal of Construction and Building Materials (2005).

[8] H. Shaheen, Y. M. Hussein and E. Fouad, Seismic Behavior of 3-D Wall Panel System, Housing and Building National Research Center HBRC, Egypt 2007.

[9] ECP 203-2007 "Egyptian Code of Practice for reinforced concrete structures" (2007)

[10] ESS "The Egyptian Standard Specification" (2009)

[11] BS EN 13163: 2001, the European Standard for EPS Thermal Insulation products for the construction industry.

[12] S. Alsheikh, "Modification of EMMEDUE M2 Building System", Concrete Research Letters (2013)

[13] ACI 318M-08 "Building Code Requirements for Structural Concrete. The American Standard Specification" (2008)

[14] CSA Standard A23.3-04 "Design of Concrete Structures. The Canadian Standard

Specification" (2004) 